\title{
A INCLUSÃO DO ALUNO COM SÍNDROME DE DOWN NA EDUCAÇÃO BÁSICA
}

\author{
MELO, Ângela Fernandes de ${ }^{1}$
}

\section{RESUMO}

O presente artigo procura apontar e entender quais os maiores desafios enfrentados na inclusão do aluno portador da Síndrome de Down dentro do contexto da Educação Básica e como é o papel do professor e seus afazeres pedagógicos para enfrentá-los, inserindo este aluno no contexto da classe regular. Esta pesquisa tem como objetivo geral investigar a Educação inclusiva dentro da Educação Básica e abordar seus desafios com crianças Down. 0 interesse pelo tema justifica-se em implementar uma discussão a respeito do trabalho com crianças com Síndrome de Down, incluídas na classe regular em escolas não especializadas no assunto, conhecer como é realizado o processo de ensino e aprendizagem e como esses alunos aprendem, pois uma criança com necessidades especiais impulsiona professores e escolas a repensar estratégias de ensino para inserção destes na sociedade. É um estudo teórico reflexivo bibliográfico, de cunho qualitativo, e se delimita ao problema da investigação. Há indicativos de que uma criança com necessidades educacionais especiais impulsiona professores e escolas a repensar estratégias de ensino para inserção destes na sociedade. A inclusão só ganha significado ao introduzir no ambiente escolar novas oportunidades para se melhorar a educação inclusiva, tornando-a de qualidade, sem prejuízos ou preconceitos.

Palavras-Chave: Educação Inclusiva - Educação Formal - Síndrome de Down.

\section{ABSTRACT}

This article seeks to point out and understand what are the biggest challenges faced in the process of inclusion of a students who is Down syndrome carrier in the context of Basic Education and what teachers roles are as well as their teaching duties to face them, inserting this student in the context of the regular class. This research aims to investigate the general inclusive education within the basic education and address its challenges with Down children. The relevance of the subject lies in implementing a discussion regarding the work with children with Down syndrome, included in regular class, non-specialized schools, and getting to know how the learning and teaching process occurs since a special-needs child drives teachers and schools to rethink strategies that can promote their insertion in society. It is a theoretical, reflective and bibliographic study of qualitative nature, that delimits the problem of research. Inclusion only gains meaning when promoting new opportunities in the school environment to improve inclusive education, making it better and more adequate without losses or prejudices.

\section{KEYWORDS: Inclusive Education - Formal Education - Down Syndrome.}

\footnotetext{
${ }^{1}$ Graduada em Licenciatura em Pedagogia na Faculdade de Educação da Universidade do Estado do Rio de Janeiro. Email: angelafernandes.melo@yahoo.com.br
} 


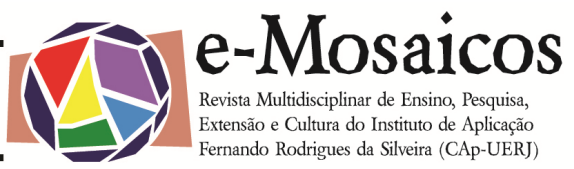

\section{INTRODUÇÃO}

Este artigo de revisão objetiva mostrar, de forma muito breve, a "A inclusão do aluno com Síndrome de Down na Educação Básica", onde serão abordados os fazeres pedagógicos aplicados através da inclusão de alunos com Síndrome de Down em conjunto com os alunos regulares. Este tema foi escolhido por apresentar uma questão pertinente às discussões sobre a inclusão escolar, pois visa mostrar as dificuldades que professores e pedagogos enfrentam em ter um aluno com Síndrome de Down em sua sala de aula. Foi percebido este problema, no Estágio realizado em escolas do ensino básico.

Com a chegada de alunos com necessidades educacionais especiais às escolas regulares, em especial de alunos com Síndrome de Down, muitos gestores e professores se frustram por não conseguirem, através do processo de ensino e aprendizagem, atingir os alunos de inclusão. Um dos maiores objetivos da Inclusão de alunos com Necessidades Educacionais Especiais (NEE) é a interação social, advinda com o aprendizado do currículo.

Meu intuito com a escolha deste tema é discutir a inclusão dos alunos com Síndrome de Down na Educação Básica e como essas crianças estão tendo acesso ao conhecimento nas escolas, inseridas em classes regulares. O problema posto aqui neste texto é tratar: como trabalhar e quais habilidades de conteúdos de disciplinas específicas do currículo, deve-se desenvolver em alunos portadores de Síndrome de Down?

Esses alunos apresentam uma construção do conhecimento das letras e dos números bem mais lenta do que os demais, porém, a compreensão de mundo é compatível com a de qualquer pessoa dita normal, seus interesses e manifestações são iguais aos de qualquer criança.

O objetivo deste trabalho é discutir a Educação Inclusiva a partir do paradigma da teoria sócio-histórica e esboçar como as crianças com Síndrome de Down estão tendo acesso ao conhecimento na escola. $\mathrm{Na}$ perspectiva sócio-histórica, as leis do desenvolvimento humano são as mesmas para todos, de forma igualitária no geral, porém enfatizando que todos nós somos diferentes (DALLA, 2003).

Vygotsky (2003) afirma que as interações sociais promovem o desenvolvimento psicológico individual, inclusive nas dimensões cognitivas superiores e que quanto mais ampla a diversidade destas, maior a riqueza no processo de construção do conhecimento. Desta forma, Vygotsky defende uma escola inclusiva para que estas crianças tenham a oportunidade de interagir com outras de classes regulares.

Esta pesquisa se justifica em implementar uma discussão a respeito do trabaIho com crianças portadoras de Síndrome de Down, incluídas na classe regular em escolas não especializadas no assunto, e desta forma conhecer como é realizado o processo ensino aprendizagem e como esses alunos aprendem, pois uma criança com necessidades educacionais especiais impulsiona professores e escolas a repensar estratégias de ensino para inserção destes na sociedade.

A pesquisa nos aponta o tamanho do desafio que as mudanças nas práticas do pedagogo implicam, seja pelo perfil e formação desses profissionais ou pela linha de pensamento dominante quanto ao seu papel na escola, atuação centrada nos fazeres pedagógicos ao inserir uma criança com Síndrome de Down em uma turma regular.

\section{ConheCEndo A SíndRome De Down}

A Síndrome de Down, segundo Dalla (2003, p. 23) "é definida por uma alteração genética caracterizada pela presença de um terceiro cromossomo de número 21 , o que também é chamado de trissomia do $21^{\prime \prime}$. Trata-se de uma deficiência carac- 
terizada pelo funcionamento intelectual inferior à média, que se manifesta antes dos 18 anos. Além do déficit cognitivo e da dificuldade de comunicação, a pessoa com Síndrome de Down apresenta redução dos tônus musculares, cientificamente chamada de hipotonia.

A origem da Síndrome de Down é de difícil identificação e engloba fatores genéticos e ambientais. As causas são inúmeras e complexas, envolvendo fatores pré, peri e pós-natais. Para Alves (2011, p. 17):

\begin{abstract}
A Síndrome de Down não é progressiva nem contagiosa. A própria flacidez muscular pode reduzir com 0 tempo por meio do trabalho de fisioterapia e pelo amadurecimento do Sistema Nervoso Central, o fator da disfunção cerebral é presente, tendo probabilidades de convulsões. Essa síndrome é conhecida como Mongolismo ou Trissomia 21, genericamente doença localizada no cérebro, encefalopatia, não progressiva, possuindo tendências para melhoras espontâneas.
\end{abstract}

Há estudos que descrevem em detaIhes as alterações que podem ocorrer com frequência, tanto na estrutura e função do cérebro de pessoas com síndrome de Down, onde esta patologia é apreciada nas primeiras fases de vida e cuidados, e podem mesmo ser aumentadas, ao longo dos anos.

A criança com Síndrome de Down necessita, acima de tudo, ser compreendida, para que possamos reconhecer suas necessidades, gostos e anseios, pois a partir daí, será mais fácil educá-la.

Seu funcionamento cerebral, o jeito de pensar, de falar, de ser, de agir está afetado por material genético extra. Cada célula humana tem todas as características do indivíduo. Elas estão agrupadas no centro. A Síndrome de Down se caracteriza por um gene a mais, fazendo a criança ter características especiais. Ela passa pelas mesmas etapas de vida que qualquer indivíduo, porém, mais lentamente.

A primeira descrição clínica foi feita em 1866 pelo médico pediatra inglês John Langdon Down, que trabalhava no Hospital John Hopkins em Londres em uma enfermaria para pessoas com deficiência intelectual, e publicou um estudo descritivo e classificou estes pacientes de acordo com o fenótipo. Descreveu como "idiotia mongólica" aqueles com fissura palpebral oblíqua, nariz plano, baixa estatura e déficit intelectual.

Para Alves (2011, p. 39) "as crianças e os jovens com Síndrome de Down podem alcançar estágios avançados de raciocínio e de desenvolvimento". E, por serem hipotônicas e flácidas, demoram mais para despertar para o mundo que as cerca, portanto, se faz necessário um envolvimento afetivo mais profundo, é preciso estimular para desenvolver as funções de alimentação por meio de técnicas derivadas, trabalhando os tônus e as habilidades motoras, que ajudarão em todas suas tarefas.

\subsection{Características E ASPECTOS CLÍNICOS, DIAGNÓSTICO E ACOMPANHAMENTO}

O diagnóstico clínico baseia-se no reconhecimento de características físicas. Quanto mais características específicas da Síndrome forem identificadas, aumenta-se a segurança do diagnóstico clínico.

O fenótipo da Síndrome de Down se caracteriza principalmente por:

Pregas palpebrais oblíquas para cima, epicanto (prega cutânea no canto interno do olho), sinófris (união das sobrancelhas), base nasal plana, face aplanada, protrusão lingual, palato ogival (alto), orelhas de implantação baixa, pavilhão auricular pequeno, cabelo fino, clinodactilia do $5^{\circ}$ dedo da mão (50 dedo curvo), bra- 
quidactilia (dedos curtos), afastamento entre $01^{\circ}$ e o $2^{\circ}$ dedos do pé, pé plano, prega simiesca (prega palmar única transversa), hipotonia, frouxidão ligamentar, excesso de tecido adiposo no dorso do pescoço, retrognatia, diástase (afastamento) dos músculos dos retos abdominais e hérnia umbilical (BRASIL, 2012, p. 15).

Nem sempre todas essas particularidades precisam estar presentes para se realizar o diagnóstico clínico. Da mesma forma que a apresentação isolada de uma dessas características não configura o diagnóstico, visto que uma boa parte da população pode apresentar algum desses sinais abordados.

Segundo Alves (2011), as crianças com Síndrome de Down:

Estão relacionadas aos Estágios do Desenvolvimento segundo Piaget, com os seguintes aspectos, aonde nos Estágios I e II que vão do nascimento até cinco ou seis meses, ainda não sabe brincar com os objetos. Já com 12 ou 24 meses, ela está no Estágio IV e percebe que um objeto pode ser posto dentro de alguma coisa. Dos 24 meses aos três anos, ela começa a combinar objetos juntando os parecidos, distribuindoos em coleções, o que mostra que ela está no Estágio V. Após os três anos, no Estágio VI, além de colecionar os objetos semelhantes, faz correspondência, agrupa-os, dividindoos como grandes e pequenos. Bem diferente de uma criança sem a síndrome que quando passa para o nível VI, já possui o cognitivo mais desenvolvido e trabalha inventando ideias e utilizando objetos imaginários, imitações, fazendo uma combinação mental (p. 50).

Segundo Maia (2011), o tratamento da criança com Síndrome de Down:
É multidisciplinar, interdisciplinar e deve incluir todos os profissionais envolvidos no atendimento à criança. Médicos (pediatras, neurologistas, psicólogos, psiquiatras, fisioterapeutas) que precisam interagir com fonoaudiólogos, psicopedagogos, psicólogos e pedagogos. Respeitando a individualidade e os limites que são diferentes e variam de criança para criança. (p. 28).

Esse acompanhamento interdisciplinar e multidisciplinar contribui para o aprendizado da criança dentro da educação infantil de forma objetiva, onde o apoio dessa equipe, em contrapartida com o apoio da família, auxilia no desenvolvimento da criança.

\section{A Prática Pedagógica junto À CRIANÇA COM SÍNDROME DE DOWN}

Por vezes, dentro de exemplos na sociedade, esbarramos com downianos que conseguem, apesar de suas dificuldades, ter uma vida secular e profissional, claro que pautados em limitações que a síndrome apresenta. E isso se deve à estimulação precoce por parte da família e por parte da escola. Essas crianças downianas, assim como as autistas, disléxicos ou mesmo com outro tipo de síndrome ou distúrbios, quando diagnosticadas e estimuladas, desde a fase infantil, apresentam melhoras incríveis e características de vida tão plenas quanto as crianças normais.

Segundo estudos de Dalla (2003), Alves (2011) e Maia (2011), têm, como dinâmica de prática pedagógica, a forma de se estabelecer a troca de conhecimento através da interação, propor à turma a realização de tarefas e trabalhos em grupos, onde a criança Downiana tenha possibilidades de se relacionar com os outros alunos, pois as tarefas e os trabalhos realizados desta forma favorecem a aproximação de alunos com e sem necessidades educacionais especiais, além de potenciali- 
e-Mosaicos - Revista Multidisciplinar de Ensino, Pesquisa, Extensão e Cultura do Instituto de Aplicação Fernando Rodrigues da Silveira (CAp-UERJ)

zar o desenvolvimento acadêmico de ambos e outros aspectos psíquicos e motores.

Ao se trabalhar com crianças com Síndrome de Down, deve-se estimular a comunicação oral/linguagem, e o desenvolvimento de outras áreas do conhecimento, como o ensino da Matemática, Ciências e outras matérias pertinentes ao currículo.

Mantoan (2003, p. 20) "salienta a relevância da utilização de tarefas com auxílio de recursos multimídia, jogos, atividades lúdicas, tecnologias assistidas e outras ferramentas que funcionem no contexto educacional", assim se dá como um importante instrumento pedagógico de auxílio no processo de ensinoaprendizagem.

Algumas atividades que pretendem explorar variadas probabilidades dentro desse campo da representação visual podem ser realizadas, utilizando-se palavras impressas como embasamento para a fala e associação de desenhos ou figuras a imagens escritas. No caso dos alunos que já estão alfabetizados, é importante a inserção de jogos, a serem vivenciados ou mesmo elaborados pelos alunos, visando enfatizar que o aprendizado que ocorre de modo lúdico é mais prazeroso, além de benefício no contexto cognitivo de qualquer criança.

Existem alguns jogos que podem ser trabalhados especificamente com crianças com Síndrome de Down, por exemplo, o Jogo da Memória, onde o professor pode confeccionar um jogo mais temático, visando a disciplina ou o gosto da criança, a partir de pares de figuras semelhantes, que representem o mesmo objeto, podendo ser produzido com desenhos, objetos, até a foto dos próprios alunos.

A criança que brinca com jogos da memória pode ter raciocínio mais rápido e capacidade de memorização mais aguçada. A criança costuma aprender mais atra- vés dos brinquedos, brincadeiras e jogos educativos, e segundo Alves (2011):

Esse estímulo melhora o comportamento diante de regras que surgem em casa, na escola e em toda sua vida, um sentido de que a regra serve apenas para organizar e tornar a vida mais fácil e não que seja algo ruim. Auxiliando também no convívio familiar e social, seja qual for o ambiente (ALVES, 2011, p. 32).

Esse estímulo através da ludicidade leva a uma grande diversidade dentro da sala de aula, e este fato bem real conduz os professores a procurarem estratégias e procedimentos que proporcionem a todos os alunos as melhores condições e oportunidades de aprenderem e interagirem, de forma mais solidária e cooperativa, desenvolvendo ao máximo as suas habilidades e proporcionando a interação entre o grupo.

As crianças com Síndrome de Down podem alcançar estágios muito mais avançados de raciocínio e de desenvolvimento. $E$ este pensamento é ratificado por meio da seguinte colocação de Alves (2011), ao ponderar que:

Em virtude da hipotonia generaliza$\mathrm{da}$, presente desde o nascimento, originada no SNC (Sistema Nervoso Central), faz-se necessário o acompanhamento fisioterápico e psicomotor, por causa dessa hipotonia afetar a musculatura e a parte ligamentar. Neste acompanhamento, ela tende a diminuir espontaneamente, mesmo que permaneça por toda a vida, em graus diferentes, levando o downiano a estágios mais avançados em seu desenvolvimento motor e cognitivo (ALVES, 2011, p. 39).

Para Dalla (2003, p. 45), a Síndrome de Down é classificada como uma deficiência mental, a qual não se pode preestabelecer o seu limite no indivíduo, mas e- 
e-Mosaicos - Revista Multidisciplinar de Ensino, Pesquisa, Extensão e Cultura do Instituto de Aplicação Fernando Rodrigues da Silveira (CAp-UERJ)

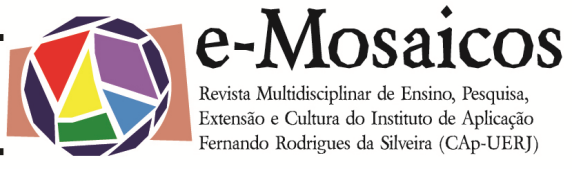

xiste grande possibilidade de desenvolvimento cognitivo.

Os estudos demonstram que existem vários exemplos de crianças com Síndrome de Down que se desenvolvem de forma motora e cognitiva, desempenhando-se muito bem no seu cotidiano escolar e até mesmo dentro da sociedade de forma ativa, constituindo família, tendo atividade remunerada, enfim, exercendo sua cidadania.

Um exemplo da possível produtividade laboral seria a atuação de três jovens com Síndrome de Down, no filme brasileiro de 2012 e que estreou em $1^{\circ}$ de março de 2013. Estrelado por três jovens downianos, com histórias de vidas, criações e tratamentos diferentes. Porém, com a mesma vontade de serem vistos pelo mundo, sem preconceito. Em entrevista com a repórter Marília Gabriela em seu programa, exibido em março de $2013^{2}$. Colegas vem a ser um filme de aventura e comédia brasileiro dirigido e roteirizado por Marcelo Galvão, que se inspirou em um downiano chamado Ariel Goldenberg, que fez a diferença em sua vida, por ser um rapaz esforçado, que não desiste facilmente de seus objetivos, e foi capaz de mobilizar meios para levantar fundos para realizar seu sonho de ser ator. Fora da ficção, esse rapaz, apesar de suas limitações pela síndrome e preconceitos sociais sofridos em sua vida, casou-se com Rita Pokk, uma Downiana que, perdeu seu pai cedo, mas tem sua mãe como apoio e sua família, e também sonha em ser uma atriz bem sucedida e almeja novos trabalhos. Outro personagem deste roteiro é Breno Viola, escolhido entre mais de 300 portadores de Down, tem uma família que sempre o apoiou e um irmão

\footnotetext{
2 Reportagem com entrevistas do diretor e os protagonistas do filme "Colegas" apresentado em 2013, sendo o primeiro filme brasileiro com atores portadores de Síndrome de Down, protagonizando papeis de destaque, em: https://www.youtube.com/watch?v=eVPfis0XOho
}

judoca que o inspirou a seguir seus passos. Seu sonho é participar das paraolimpíadas. Focado, bem articulado em sua fala, não consegue gravar muito bem seus textos, mas é audacioso e cativante, ganhando o papel pela sua arte em improvisar e boa articulação da fala.

O filme, lançado em 2013, foi vencedor de inúmeros prêmios em importantes festivais de cinema no Brasil, Estados Unidos, Canadá, Rússia, Itália, Portugal e Chile. $E$, segundo reportagem ${ }^{3}$, também teve participação como filme de abertura na categoria hors-concours em diversos festivais de cinema no mundo.

Alguns sujeitos com Síndrome de Down apresentam dificuldades motoras e comprometimento intelectual. Porém, ao serem estimulados desde pequenos, por seus pais e terem acesso a tratamentos adequados às suas necessidades, assim como serem frequentadores de escolas regulares, podem ter sua plasticidade cerebral ativada e assim apresentam reduções significativas de suas limitações. Sendo tratados como normais, passam a apresentar características de uma vida normal.

Além do exemplo dos jovens do longa de cinema citado, temos também o caso de sucesso, acontecido na época da novela "Páginas da Vida", onde a pequena atriz Joana Morcazel, filha do cineasta Evaldo Mocarzel e da produtora Letícia Mocarzel, aos seis anos, participou de algumas cenas da novela de Manoel Carlos. O propósito do autor era apresentar, na trama, o preconceito sofrido pelas crianças portadoras da Síndrome de Down e sua inclusão numa escola regular.

Com esses e outros vários exemplos, não citados, o que fica claro, é que, para que isso ocorra, há a necessidade de se fazer um acompanhamento da criança

3 http://redeglobo.globo.com/acao/noticia/ 2013/03/como-no-filme-colegas-tres-jovenscorrem-em-busca-dos-seus-sonhos.html 
e-Mosaicos - Revista Multidisciplinar de Ensino, Pesquisa, Extensão e Cultura do Instituto de Aplicação Fernando Rodrigues da Silveira (CAp-UERJ)

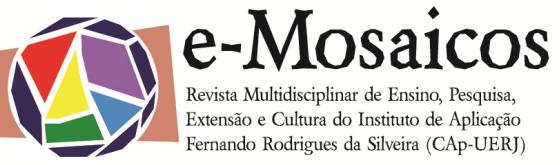

desde Educação Infantil, pois, estudos têm mostrado que o comprometimento no desenvolvimento, tanto biológico, quanto social da criança com Síndrome de Down, pode ser minimizado através da estimulação precoce de suas capacidades, a fim de torná-la uma cidadã participativa.

As pessoas com Síndrome de Down, segundo Voivodic (2004), como qualquer outra pessoa:

Tem seu desenvolvimento, psíquico, motor, social, determinado pelos contextos sociais em que vivem e pelas peculiaridades idiossincráticas de cada uma, por isso, é importante que o professor, a escola e os pais, tenham conhecimento sobre as dificuldades e capacidades da criança, para desenvolver um trabalho pedagógico (p. 27).

Na abordagem de Silva (2001), é importante que, por meio de atividades terapêuticas, sejam trabalhados com as pessoas que apresentam Síndrome de Down:

A cooperação, organização, constituição, movimentos, autonomia, compreensão, exploração, com propostas lúdicas e materiais diversos e, por meio de comandos, sejam realizadas atividades motoras, como correr, pular, rolar, subir, descer, rasgar, pintar, empilhar, colar, picotar, amassar, arrastar, manusear, desenhar, reconhecer cores e formas, facilitando o desenvolvimento social, afetivo, cognitivo, motor, da linguagem, de grafismo, dos hábitos e das atitudes ( $p$. 40).

Mães e pais de crianças com Síndrome de Down defendem, cada vez mais, a presença de profissionais que atuem como mediadores do aprendizado dos fiIhos em unidades regulares de ensino. A discussão sobre a presença de um auxiliar/cuidador, dentro da sala de aula moti- vou a apresentação do Projeto de Lei no $8.014 / 10$, que foi aprovado no Congresso. Sendo assim, as escolas públicas e privadas terão que manter um educador a mais na sala de aula, para atender alunos com deficiência intelectual ou física, o que auxilia o trabalho do professor.

A Atual Constituição Federal, em seu artigo 208, garante a universalização do atendimento especializado a alunos com deficiência na rede de ensino regular, com educação inclusiva e estabelece o direito à integração plena dessas pessoas em todas as áreas da sociedade.

É neste aspecto que, em sua teoria, Vygotsky (1997, apud, SILVA, 2001, p. 41) "destaca a importância do mediador social, o qual é parte do meio em que o indivíduo interage e, assim, é quem tende a influenciar diretamente no desenvolvimento destas crianças", seja no âmbito intelectualcognitivo ou sociocultural, propiciando um ambiente escolar harmônico e cheio de estímulos, auxiliando na aprendizagem através de alunos e professores.

Na concepção empregada por Mantoan (2003, p.23), "a inclusão escolar tem sido mal compreendida, principalmente no seu apelo às mudanças nas escolas comuns e especiais".

E ainda, segundo esta autora, a inclusão se propõe:

A encontrar soluções que respondam à questão do acesso e da permanência dos alunos nas suas instituições educacionais e também da continuidade dos estudos por uma pessoa que, mesmo com dificuldades, falta de apoio e preconceito, busca a escola como uma saída, um refúgio ou um apoio especializado para a sua necessidade especial. E é no momento em que um aluno tem acesso à escola comum que ocorrem os conflitos. O aluno "diferente" desestabiliza o pensamento moderno da escola, na sua ânsia pelo lógico, pela negação das condições que produzem as dife- 
e-Mosaicos - Revista Multidisciplinar de Ensino, Pesquisa, Extensão e Cultura do Instituto de Aplicação Fernando Rodrigues da Silveira (CAp-UERJ)

renças, que são as matrizes da nossa identidade (MANTOAN, 2003, p.18).

Acredita-se que a educação inclusiva significa proporcionar a todos os alunos, sem exceção, a igualdade de oportunidades e direitos na educação, independentemente da sua origem, da sua condição física e psicológica e da sua capacidade de aprendizagem. Isto para que todos tenham a oportunidade de usufruir dos serviços educativos de qualidade, de forma a poderem preparar-se para uma vida futura o mais autônoma e produtivamente possível, longe de preconceitos e estereótipos.

\section{ConstruçÃo de saberes de UMA CRIANÇA COM SÍNDROME DE DOWN}

Para Dalla (2003, p. 53), "o portador da Síndrome de Down é capaz de compreender suas limitações e conviver com suas dificuldades". Essa criança apresenta um ritmo de aprendizagem mais lento, porém sua cognição, memória e competência de aprender podem ser desenvolvidas com estímulos apropriados, por isso existe a necessidade de tratá-la desde cedo.

O estímulo e o tratamento precoce são importantes em qualquer tipo de necessidade especial. Toda criança, ao demonstrar algum tipo de problema, tem seu desenvolvimento mais vagaroso como característica, quando confrontados às crianças que não apresentam nenhum distúrbio, cabendo, assim, aos pais e educadores a responsabilidade de diagnosticálos e a função de excitá-los por meio de atividades e exercícios lúdicos, visando prepará-los para a aprendizagem de capacidades mais complicadas.

As pessoas com Síndrome de Down podem atuar em níveis muito mais elevados do que se acreditava há alguns anos atrás, onde a concepção dos limites impostos por sua condição genética básica demostrou uma gama de variantes intelectuais e físicas, sendo que estes indivíduos possuem características parecidas, porém, uns possuem um empenho maior do que outros, mas mesmo os de Q.I., mais deficitário chegam a surpreender quando estimulados (PUESCHEL, 2003).

Segundo Sanches (2010, p. 32), a intervenção precoce objetiva promover "o desenvolvimento sensório-motor e social do bebê, na busca de criar condições meIhores para que a criança pequena aproveite ao máximo as aprendizagens que vivencia em seu mundo social". Para que a criança com síndrome de Down adquira habilidades motoras, tem de superar sua fraqueza muscular e os tônus musculares pobre ou hipotonia que dificultam o uso dos membros e do tronco, características da síndrome.

A criança Down deve ser atendida por uma equipe multidisciplinar contendo basicamente profissionais de fisioterapia, fonoaudiologia, pedagogia, terapia ocupacional e psicologia.

Na pré-escola, entre seus 3 e 5 anos, a criança Down pode apresentar uma larga abrangência de desenvolvimento nas habilidades diárias, na coordenação motora grossa e fina, no desenvolvimento da fala e na convivência social. É necessário, porém, que o programa educacional escolar seja adaptado às suas habilidades e necessidades especiais, assim como é importante que a escola promova, nessas crianças, uma identidade pessoal positiva que contemple sua autoestima e respeito entre os colegas (SANCHES, 2010).

Na Síndrome de Down, a criança apresenta idade cronológica diferente da idade funcional, por isso, não é possível se esperar uma resposta semelhante à apresentada por crianças que não acomodam alterações de aprendizagem, a conexão dos processos neurológicos e da entoada evolução de funções, especifica como linguagem, percepção, esquema corporal, orientação temporo-espacial e lateralida- 
de, além de não aumentarem táticas espontâneas voltadas ao processo de aquisição de aprendizagem, fazendo que estas tenham muitas dificuldades em resolver problemas e encontrar soluções sozinhas.

Outros agravantes que prejudicam a aprendizagem da criança Down são deficiências da síndrome que acometem e implicam na dificuldade ao desenvolvimento da aprendizagem, como as alterações auditivas e visuais, incapacidade de organizar atos cognitivos e condutas, debilidades de associar e programar sequências, imaturidade nervosa e não mielinização das fibras, que podem dificultar funções mentais como: habilidade para usar conceitos abstratos, memória, percepção geral, habilidades que incluam imaginação, relações espaciais, esquema corporal, habilidade no raciocínio, estocagem do material aprendido e transferência na aprendizagem, onde estas deficiências proporcionam debilidades que dificultam principalmente as atividades escolares (DALLA, 2003).

Na concepção de Pueschel (2003, p. 32), "não há um padrão estereotipado previsível nas crianças com Síndrome de Down", e é importante que elas sejam colocadas em uma situação onde consigam um desempenho escolar no mínimo satisfatório ou que se evite preventivamente a perpetuação do erro e do fracasso. Não há vários níveis graduais de Síndrome de Down, existem, sim, diferenças em virtudes das capacidades intelectuais, como as pessoas ditas normais. $O$ incentivo é sempre a melhor opção.

A criança com Síndrome de Down é capaz de entender muito bem as coisas com naturalidade. Não é necessário um linguajar especial nem atitudes e comportamentos diferentes para lidar com ela. As atividades físicas, como esportes e lazer, são de fundamental importância para uma boa qualidade de vida.

\section{CONCLUSÃo}

As reflexões sobre a inclusão do aluno com Síndrome de Down, em classes regulares, visaram abordar as dificuldades e os trabalhos pedagógicos realizados através da inclusão. As informações são de cunho bibliográfico e informativo sobre as possibilidades de desenvolvimento social e educativo dos downianos.

Foram apontados, desde a necessidade de uma formação contínua dos educandos estruturados em conhecimentos sobre a síndrome e a elaboração de atividades específicas e diferenciadas de acordo com o caso, adaptando-as ao currículo, até uma estruturação adequada da escola para receber, não só alunos com Síndrome de Down, como também alunos com outras necessidades.

Apesar de a grande maioria dos professores estar condicionada a tendências pedagógicas que foram incorporadas para priorizar o senso comum do trabalho tradicional, a inclusão deve ser observada como uma educação igualitária e deve ser primada pela qualidade, que só é adquirida com a incessante busca do conhecimento continuado.

Em salas de aulas integradas, todas as crianças se estruturam e se enriquecem, por terem a oportunidade de aprender umas com as outras. Desta forma, a criança necessita, acima de tudo, ser compreendida, para que, ao reconhecer suas necessidades, gostos e anseios, se possa realizar, um trabalho mais adequado, e assim será mais fácil educá-la. Deve-se ter em mente que a Síndrome de Down não é progressiva, nem contagiosa, como às vezes é vista, mas que é uma diferença que faz com que a criança tenha necessidade de cuidados diferenciados, porém, de tratamento igualitário, pois esta, quando bem estimulada, pode ter uma qualidade de vida melhor, a ponto de ser normal, mesmo com suas diferenças.

O apoio da família é muito importante, assim como a presença de profissionais que atuem como mediadores do aprendi- 
zado. Existe a necessidade de tratá-la, desde cedo, com atividades e acompanhamentos com especialistas, mesmo após a inserção da criança na escola, buscando desenvolver sua forma motora e cognitiva, para que se desempenhe meIhor, no cotidiano escolar, e até mesmo dentro da sociedade de forma ativa, podendo até vir a constituir família, e ter atividade remunerada, enfim, ter os mesmos direitos de uma pessoa dita normal.

Uma das formas de trabalho pedagógico, com crianças com Síndrome de Down, é o estímulo através da ludicidade, que pode levar a uma grande diversidade dentro da sala de aula, e este fato conduz os professores a procurarem estratégias e procedimentos que proporcionem, a todos os alunos, uma melhor forma de compreensão dos conteúdos. Não há um padrão estereotipado previsível, nas crianças com Síndrome de Down. É importante que elas sejam colocadas em uma situação onde consigam um desempenho escolar no mínimo satisfatório.

Acredita-se, portanto, que a educação inclusiva significa proporcionar a todos os alunos, sem exceção, a igualdade de oportunidades e direitos, independentemente da sua origem, da sua condição física, social e psicológica e da sua capacidade de aprendizagem. Isto para que todos tenham a oportunidade de ter o direito a exercer sua cidadania de forma plena, e igualitária, conforme prediz nossa Constituição.

\section{REFERÊNCIAS BIBLIOGRÁFICAS}

ALVES, Fátima. Para entender Síndrome de Down. 2. a ed., Rio de Janeiro: Wak Editora, 2011.

BRASIL. Ministério da Saúde. Secretaria de Atenção à Saúde. Departamento de Ações Programáticas Estratégicas. Diretrizes de atenção à pessoa com Síndrome de Down. Ministério da Saúde, Secretaria de Atenção à Saúde, Departamento de Ações Programáticas Estratégicas. - Brasília: Ministério da Saúde, 2012.

DALLA, Vanessa Helena Santana Dea. DUARTE, Edson (orgs.). Síndrome de Down informações, caminhos e histórias de amor. São Paulo: Editora Phorte, 2003.

MAIA, Herber. (orgs.). Necessidades Educacionais Especiais. Rio de Janeiro: Wak Editora, 2011.

MANTOAN, Maria Teresa Egler. Inclusão Escolar - O que é? Por quê? Como fazer? São Paulo: Editora Moderna, 2003.

PUESCHEL, Siegfried (org.). Síndrome de Down: Guia para Pais e Educadores. 8 ed. Campinas, São Paulo: Papirus, 2003.

SANCHES, Pilar Arnaiz, Marta Rabadán Martínez e Iolanda Vives Peñalver; trad. Inajara Haubert Rodrigues. A psicomotricidade na educação infantil: uma prática preventiva e educativa. Porto Alegre: Artmed, 2010.

SILVA, Shirley e VIZIM Marli (org.). Educação Especial: Múltiplas leituras e diferentes significados. Campinas, SP: Mercado de Letras: Associação de Leitura do Brasil - ALP, 2001.

VOIVODIC, Maria Antonieta M. A. Inclusão Escola de crianças com Síndrome de Down. Petrópolis, RJ: Editora Vozes, 2004. 